\title{
Spinal melanotic schwannomas
}

\author{
Schwanomas melanocíticos intra-raquidianos \\ Leonardo C. Wellingㄴ, Vinicius M. P. Guirado², Marcelo Tessari ${ }^{1}$, Alexandre R. Felix, Cristina Zanellato ${ }^{3}$, \\ Eberval G. Figueiredo4, Mario Augusto Taricco ${ }^{4}$, Manoel Jacobsen Teixeira ${ }^{5}$ \\ ${ }^{1} \mathrm{MD}$, Department of Neurosurgery, Bom Jesus Hospital, Ponta Grossa PR, Brazil; \\ ${ }^{2}$ MD, Department of Neurosurgery, School of Medicine, University of São Paulo (USP), São Paulo SP, Brazil; \\ ${ }^{3} \mathrm{MD}$, Sample Laboratory, Bom Jesus Hospital, Ponta Grossa PR, Brazil; \\ ${ }^{4}$ MD, PhD Department of Neurosurgery, School of Medicine, USP, São Paulo SP, Brazil; \\ ${ }^{5}$ MD, PhD Full Professor, Department of Neurosurgery, School of Medicine, USP, São Paulo SP, Brazil. \\ Correspondence: Leonardo C. Welling; Rua Tiradentes 976; 84010-190 Ponta Grossa PR - Brasil; E-mail: leonardowelling@yahoo.com.br \\ Conflict of interest: There is no conflict of interest to declare. \\ Received 06 August 2011; Received in final form 01 September 201; Accepted 09 September 2011
}

Schwannomas are solitary, benign, slow-growing, encapsulated neoplasms composed of differentiated neoplastic Schwann cells. The melanocytic schwannoma, a schwannian tumor variant, is rarely encountered and its ocurrences have been described as single case reports ${ }^{1}$. The most common site of these tumors is the posterior spinal nerve root ${ }^{1,2}$. However, they can occur in other locations, such as the sympathetic chain, acoustic nerve, cerebellum, orbit, choroid, soft tissues, heart, oral cavity, esophageal wall, stomach, bronchus, retroperitoneum, uterine cervix and parotid gland ${ }^{2,3}$. The melanotic schwannomas can be related as a part of a syndrome named Carney complex (described in 1990), characterized by the association of cutaneous pigmentation, fibromyxoid tumors of the skin, myxoma of the heart, endocrine overactivity and autosomal dominant inheritance ${ }^{4}$. The largest series in spinal melanotic schwanommas is composed by 5 cases. In these series, we report our experience with three cases.

\section{CASES}

Three cases of spinal melanotic schwannoma were studied between 2006 and 2010 in authors' institution. None of the patients had a familial history or any component of Carney complex (spotty pigmentation, endocrine overactivity or myxomas).

The patients were two male and one female. The mean age was 50 years (range 42-59 years). The most frequent symptom was pain followed by motor deficit. The mean duration of symptoms was 15 months. Magnetic resonance images showed intradural, extramedullary lesions iso/hyperintense in T1- (Fig A) and hypointense in T2weighted sequences.
The histological examination revealed fusiform and epithelioid cells, with highly pigmented cytoplasm (Fig B). Immunohistochemical studies revealed intense cytoplasm and nuclear expression of S100 protein (Fig C), HMB-45 and Melan-A (Fig D).

\section{DISCUSSION}

Generally, melanotic schwannomas affect spinal nerves, the central nervous and the autonomous nervous system, but extra-nervous locations also occur ${ }^{1}$. The dorsal location represents $30.5 \%$ of the spinal melanotic schwannomas and clinical presentation is similar to other extramedullary spinal tumors ${ }^{5}$. Psammomatous melanotic schwannoma is a distinct clinicopathologic entity and may be considered as a part of the Carney complex, which is characterized by myxomas (heart, skin and breast), mucocutaneous spotty pigmentations and endocrine overactivity (due to thyroid dysfunction or hypophysial adenoma, or Cushing's syndrome secondary to primary pigmented nodular adrenocortical hyperplasia) ${ }^{4}$. About $50 \%$ of patients with melanotic psammomatous schwannomas are affected by the syndrome of Carney and one-fifth of them present multiple lesions ${ }^{1}$. None of our patients exhibits these manifestations.

The preoperative diagnosis is based on magnetic resonance imaging. While conventional schwannomas are hypointense on T1-weighted and hyperintense on $\mathrm{T} 2$-weighted sequences, the melanotic variant is hyperintense on $\mathrm{T} 1$ - and hypointense on T2-weighted sequences ${ }^{1}$.

Zhang et al. ${ }^{3}$ demonstrated that melanotic schwannomas recurred after resection in $18.2 \%$ of patients and metastasis was seen in $9.1 \%$ of the cases ${ }^{3}$. 
Our experience suggests a wide local excision to prevent additional growth and possible metastasis of the recurrent tumor. The value of radiotherapy is uncertain and the differential diagnosis is important for correct management. More studies are necessary to understand the natural history, prognosis and best management strategies.
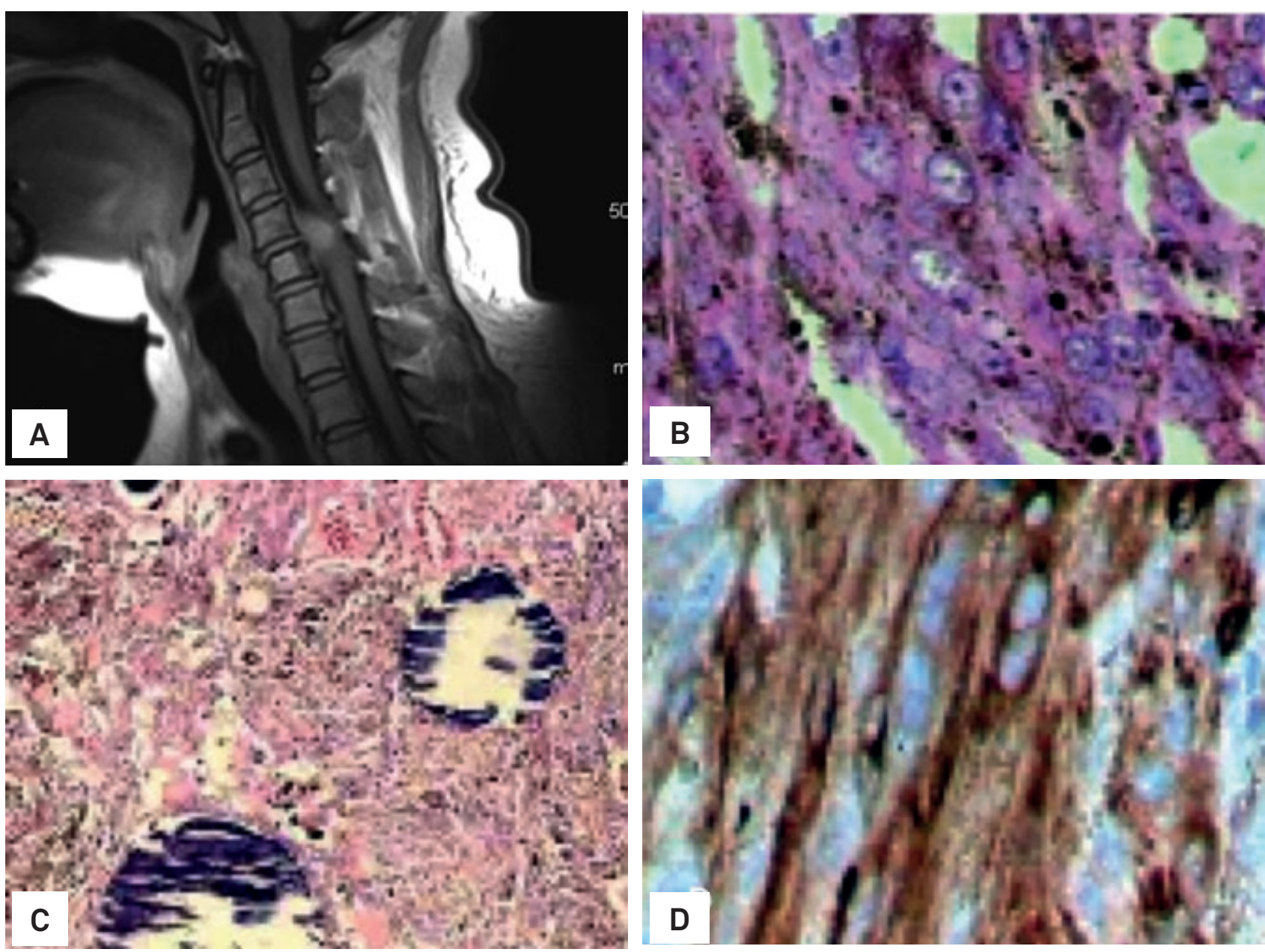

Fig. Magnetic resonance images showed intradural, extramedular lesions isointense/hyperintense in T1 (A). The histological examination revealed fusiform and epithelioid cells, with highly pigmented cytoplasm (B). Immunohistochemical studies revealed intense cytoplasm and nuclear expression of S100 protein (C), HMB-45 and Melan-A (D).

\section{References}

1. Marton E, Feletti A, Orvieto E, Longatti P. Dumbbell-shaped C2 psammomatous melanotic malignant schwannoma. Case report and review of the literature. J Neurosurg Spine 2007;6:591-599.

2. Santaguida C, Sabbagh AJ, Guidot MC, Del Maestro RF. Agressive intramedullary melanotic schwannoma: case report. Neurosurgery 2004;55:1430-1434.

3. Zhang HY, Yang GH, Chen $\mathrm{HJ}$, et al. Clinicopathological, immunohistochemical, and ultrastructural study of 13 case with melanotic schwannoma. Chin Med J 2005:118:1451-1461.

4. Carney JA. Psammomatous melanotic schwannoma. A distinctive, heritable tumor with special associations, including cardiac myxoma and the cushing syndrome. Am J Surg Pathol 1990;14: 206-222.

5. Vallat-Decouvelaere AV, Wassef M, Lot G, Catala M, Moussalam M, Caruel N. Spinal melanotic schwannoma: a tumor with poor prognosis. Histopathology 1999;35:558-566 